\title{
Olive tree blossom polyphenolic extracts exert antioxidant and antimutagenic activities in vitro and in various cell lines
}

\author{
PARASKEVI KOUKA ${ }^{1}$, FOTIOS TEKOS ${ }^{1}$, KALLIOPI VALTA ${ }^{1}$, PANAGIOTIS MAVROS ${ }^{2}$, ARISTIDIS S. \\ VESKOUKIS $^{1}$, APOSTOLIS ANGELIS ${ }^{2}$, ALEXIOS-LEANDROS SKALTSOUNIS ${ }^{2}$ and DEMETRIOS KOURETAS ${ }^{1}$ \\ ${ }^{1}$ Department of Biochemistry and Biotechnology, University of Thessaly, 41500 Larissa; ${ }^{2}$ Department of \\ Pharmacognosy and Natural Products Chemistry, Faculty of Pharmacy, University of Athens, 15771 Athens, Greece
}

Received July 8, 2019; Accepted August 12, 2019

DOI: $10.3892 /$ or.2019.7386

\begin{abstract}
Olive oil has held a prominent place in the Mediterranean diet since ancient times due to its beneficial effects on human health thus, becoming the subject of great scientific interest. Although numerous studies have examined the biological action of olive and olive oil extracts, the literature lacks studies investigating the putative antioxidant capacity of olive tree flower extracts. Given that olive tree flowers are actually by-products of the olive oil production process with high waste burden for the environment, it becomes evident that their exploitation could increase their added value. Therefore, in this study the potential antioxidant action of four olive flower extracts was investigated. All the extracts exerted potent antioxidant activity as indicated using the $\mathrm{DPPH}^{\bullet}$ and $\mathrm{ABTS}^{\bullet+}$ assays, as well as antigenotoxic and antimutagenic properties, identified by the results of the plasmid relaxation assay and the Ames test, respectively. Furthermore, the extracts also improved redox status of four cell lines (i.e., EA.hy926, $\mathrm{C} 2 \mathrm{C} 12, \mathrm{HeLa}$, and HepG2) enhancing reduced glutathione and reducing reactive oxygen species levels using flow cytometry. Taking into account that during olive tree cultivation a considerable amount of olive flowers is generated, the waste burden is high and the management is difficult. Given the optimistic findings of the present study, we believe that the flower-derived extracts may have high added value since they could be used as antioxidants or as foodstuff, food additives and functional food constituents.
\end{abstract}

\section{Introduction}

Olive tree cultivation has been a common practice for humans since $6,000 \mathrm{BC}$. Its products are widely used by residents of

Correspondence to: Professor Demetrios Kouretas, Department of Biochemistry and Biotechnology, University of Thessaly, Viopolis, Mezourlo, Larissa 41500, Greece

E-mail:dkouret@uth.gr

Key words: cell lines, olive blossoms, flowers, olive, antioxidants, polyphenols the countries in the Mediterranean basin for food, religious and medicinal applications (1). The olive tree (Olea europaea. L) is one of the most extensively cultivated species worldwide, spread over an area of 10 million hectares (2). Except for olives and olive oil, other parts of the olive tree, such as blossoms and leaves have also attracted attention. Previous findings have highlighted the health effects of leaves, which comprise $10 \%$ of the total olive weight (3). Specifically, olive leaves have been used against various diseases, since it has been reported that they possess antioxidant and antimicrobial activities, vasodilator and hypoglycaemic effects $(3,4)$. Additionally, extracts derived from olive leaf have been used as foodstuff, food additives and functional food constituents as they are rich in polyphenols (4).

Polyphenolic compounds are secondary metabolites of plants that contribute to bitterness, astringency, color, flavor, odor, flower pollination and oxidative stability, and also protect against various pathogens and UV radiation (5). Furthermore, polyphenols and foods enriched in them belong to the main scope of research activity worldwide due to their putative advantageous effects on human health, as regards their anticancer, antidiabetic and antiatherogenic properties (5). The flower is a part of the plant that contains a great variety of natural antioxidants, such as phenolic acids, anthocyanin, flavonoids and many other phenolic compounds. It has been previously shown that, oleuropein aglycon $(1.158-3.746 \mathrm{~g} / \mathrm{kg}$ ), hydroxytyrosol (HT) (0.168-1.581 $\mathrm{g} / \mathrm{kg})$ and oleoside $(0.143-1.325 \mathrm{~g} / \mathrm{kg})$ are the predominant phenolics in extracts originating from the olive flower during several developmental stages (e.g., green bud stage, white bud stage, recently opened flower stage, dehiscent anther stage and at the stage where the anthers and petals are abscised) (6). Olive blossoms have not yet been fully investigated for their potential medicinal uses. It has to be mentioned that a mature olive (Olea europaea. L) tree produces approximately 500,000 flowers but only 1-2\% of them set fruits that reach maturity (7). Each inflorescence contains 15-30 flowers, depending on the cultivar (2). Notably, fruit growth that occurs from $1 \%$ of the entire flower population is sufficient for the production of a good commercial crop $(7,8)$.

Nutrition, growth regulators, and environmental factors, including temperature and light, have an impact on floral bud induction and differentiation in olive. Specifically, the optimum temperature for best flowering seems to be $10-13^{\circ} \mathrm{C}$ for a period of 9-10 weeks. However, sensitivity to light seems 
to be cultivar-dependent, thus some cultivars require less light for the transformation of buds to flowers (9). Additionally, nutrients are dependent on fruit load, thus sodium and potassium concentrations are decreased when the fruit load is high, whereas calcium levels are increased. Finally, the high levels of chlorogenic acids induce the transformation of buds to flower (9).

The olive blossom phenotype depicts an annual cycle, characterized by the bud formation during the preceding summer, dormancy during winter, budburst in late winter, and structural development of flowers, from budburst to spring. The sexual reproduction of the olive tree is underlined by earnest phenomena such as alternate bearing, pistil abortion, and the reproductive self and cross-incompatibility (10). The olive floral buds differentiate into inflorescences during winter and floral bud differentiation during February. Differentiation occurs in late February and bloom in May when the formation of each flower part responds to the inflorescence. There are also olive (Olea europaea. L) cultivars that are almost completely self-incompatible, where the flowers are not fertilized by pollen of the same cultivar (9). The level of the fruit set seems to be independent form the amount of flowers and the number of inflorescence, when a tree enters an 'ON' year where the flowering depicts the maximum percentage (7).

Olive oil production is a physiological process, nevertheless it is clear that it is accompanied by an extensive enhancement in the amount of olive oil by-products, which are serious waste agents causing environmental problems (11). Thus, it is imperative to develop new ways to utilize such by-products in order to protect the environment (11). Olive oil, fruit and leaves have a well-known chemical composition and have been extensively studied for their biological activities. However, less attention has been given to olive tree flowers and especially those derived from wild olive varieties for which higher phenolic content is expected. The olive flower production occurs on a large scale although a small amount of blossoms produce a mature crop. Specifically, after petal drop $25 \%$ of the ovaries remain, but only $2 \%$ of the floral entities become a mature fruit (7). Therefore, our aim was to evaluate the biological effects of four polyphenolic olive floral extracts (3 from the olive varieties Lianolia and Koroneiki and one from a wild olive variety), with an holistic in vitro approach using both chemical-based and cell culture-based tests. Owing to the difficulties in the production of purified phenolic compounds and given that extracts from mixtures usually exhibit stronger antioxidant activities compared with individual molecules, our interest was focused on the use of mixture plant extracts rather than single compounds. Our ultimate aim was to shed light on the antioxidant, antigenotoxic and antimutagenic potential of the floral extracts in order to develop new products derived from the extracts with pharmaceutical, nutritional and cosmetic applications.

\section{Materials and methods}

Chemicals and reagents. Dulbecco's modified Eagle's medium (DMEM), L-glutamine, penicillin, streptomycin, fetal bovine serum (FBS), phosphate-buffered saline (PBS), 2',7'-dichlorofluorescein diacetate (DCF-DA), mercury orange, and trypsin were purchased from Gibco. Cell proliferation kit II
(XTT assay; Roche) was purchased from Roche Diagnostics. Ethanol (EtOH) was purchased from Carlo Erba Reactifs SDS. Methanol $(\mathrm{MeOH})$ was obtained from Fisher Scientific UK. All the solvents were of analytical grade. Distilled water was used to prepare all aqueous solutions. $\mathrm{H}_{2} \mathrm{O}$ was purchased from Macron Fine Chemicals [high-performance liquid chromatography (HPLC) grade] and 2,2'-azobis (2-methyl-propionamide) dihydrochloride (AAPH) was purchased from Sigma-Aldrich.

Plant material and extraction procedure. Four different samples of olive flowers belonging to Greek varieties were collected. More specifically, two of these samples (KTKT and ANKT) belong to the variety Lianolia from Corfu Island with collection dates 5-6/5/17 and 14-15/5/17, respectively. The third sample (AGRI) consists of flowers of the olive wild tree, collected on 13-14/5/17 from the island of Corfu. The final sample of olive flowers (EKPA) belongs to the variety Koroneiki and was collected on 13/5/17 from the area of the National and Kapodistrian University of Athens. The samples were collected under conducive conditions (hot and dry weather). Drying of the samples was carried out for 20 days in a dry, dark, and well-ventilated room. At the end of 20 days, the plant material was stored in the herbarium.

Subsequently, $20 \mathrm{~g}$ of each dry sample were extracted with $150 \mathrm{ml}$ of $\mathrm{EtOH} / \mathrm{H}_{2} \mathrm{O}(50: 50 \mathrm{v} / \mathrm{v})$ for $30 \mathrm{~min}$ in an ultrasonic bath (Branson 2510). The above procedure was repeated twice for each sample. Subsequently, vacuum filtration was carried out and evaporation at $40^{\circ} \mathrm{C}$ in RotaVapor until EtOH removal. The extracts were initially stored in the freezer at $-80^{\circ} \mathrm{C}$ for $24 \mathrm{~h}$ and then lyophilized on a Christ Alpha 1-5 lyophilizer (Martin Christ $\mathrm{GmbH}$ and $\mathrm{CoHG}$ ).

HPLC analysis of the extracts. HPLC device(Thermo Finnigan) was used for the qualitative and related quantitative analysis of the extracts and comprised a SpectraSystem P4000 pump, a SpectraSystem 1000 Degasser, a SpectraSystem AS3000 automatic sampling probe, and SpectraSystem UV6000LP detection probes (PDAs). Subdivision of the substances was performed on a Supelcosil RP-18 C18 chromatographic layer $25 \mathrm{~cm}$ x $4.6 \mathrm{~mm}$ i.d., $5.0 \mu \mathrm{m}$ (Discovery). The mobile phases used were water with acetic acid $(0.1 \%)$ (phase A) and acetonitrile with $\mathrm{MeOH}(2 \%)$ (phase B). The solvent gradient changed according to the following conditions: from 0 to $15 \mathrm{~min}, 95 \%$ (A): $5 \%$ (B) to $85 \%$ (A): $15 \%$ (B); from 15 to $40 \mathrm{~min}, 85 \%$ (A): $15 \%$ (B) to $55 \%$ (A): $45 \%$ (B); from 40 to $50 \mathrm{~min}, 55 \%$ (A): $45 \%$ (B) to $5 \%$ (A): $95 \%$ (B); from 50 to $55 \mathrm{~min}, 5 \%(\mathrm{~A})$ : 95\% (B) to $5 \%$ (A): $95 \%$ (B); from 55 to $56 \mathrm{~min}, 5 \%$ (A): $95 \%$ (B) to $95 \%(\mathrm{~A}): 5 \%(\mathrm{~B})$; from 56 to $60 \mathrm{~min}, 95 \%(\mathrm{~A}): 5 \%(\mathrm{~B})$ to $95 \%$ (A): $5 \%$ (B). The flow of the mobile phase was set at $1 \mathrm{ml} / \mathrm{min}$, and the injection volume of the samples was set to $10 \mu \mathrm{l}$. The detection of the eluted metabolites was performed using a PDA detector $(254,280$ and $355 \mathrm{~nm})$. For the related quantitative analysis $10 \mathrm{mg}$ of each extract was diluted in 1 $\mathrm{ml}$ of $\mathrm{MeOH}$ and the samples were analyzed in triplicate. The chromatogram analysis and the peak area calculation were performed at $254 \mathrm{~nm}$.

Assays of in vitro redox biomarkers

Determination of the total phenolic content (TPC). Total phenolic content was determined using Folin-Ciocalteu 
colorimetric method as presented previously by Blainski et al (12), according to which: $10 \mathrm{mg}$ of gallic acid (97\% purity) was dissolved in $1 \mathrm{ml}$ of DMSO and serial solutions of decreasing concentration were prepared $(1,0.8,0.7,0.5,0.4,0.3,0.2$ and $0.1 \mathrm{mg} / \mathrm{ml}$ ). After the addition of the Folin-Ciocalteu reagent, absorbance of the samples was measured at $765 \mathrm{~nm}$ using a spectrophotometer (TECAN Infinite M200 Pro UV/ Vis Reader). For the construction of the reference curve, the absorbances corresponding to the linear region of the curve were selected $\left(\mathrm{y}=0.0479 \mathrm{x}+0.2653, \mathrm{R}^{2}=0.9996\right)$. Then, $10 \mathrm{mg}$ of each extract was dissolved in $1 \mathrm{ml}$ of DMSO and serial solutions of decreasing concentration were prepared $(5,2.5$ and $1.25 \mathrm{mg} / \mathrm{ml}$ ). In each cell of the 96-well plate was transferred $25 \mu \mathrm{l}$ of each sample dissolved in DMSO, $125 \mu \mathrm{l}$ of Folin-Ciocalteu solution ( $2.5 \mathrm{ml}$ of distilled $\mathrm{H}_{2} \mathrm{O}$ contains 0.25 $\mathrm{ml}$ of Folin-Ciocalteu solution reagent) and $100 \mu \mathrm{l}$ of $7.5 \%(\mathrm{w} / \mathrm{v})$ aqueous sodium carbonate solution that acts as a promoter of the reaction. After appropriate agitation the samples remained in the dark for $30 \mathrm{~min}$ at $25^{\circ} \mathrm{C}$ and the absorption was measured by a spectrophotometer set at $765 \mathrm{~nm}$ (TECAN Infinite M200 Pro UV/Vis Reader). The total phenolic content was expressed as milligrams of Gallic Acid (GA) equivalent per gram of the olive flower extract $\left(y=0.0479 x+0.2653, R^{2}=0.9996\right)(15)$.

2,2-Diphenyl-1-picrylhydrazyl (DPPH) radical scavenging assay. The radical scavenging capacity (RSC) of the blossom extracts was evaluated using the DPPH• assay (13) with slight modifications, as previously described $(14,15)$. Briefly, $1 \mathrm{ml}$ of freshly prepared methanolic solution of DPPH $\bullet(100 \mu \mathrm{M})$ was mixed with the tested extracts at various concentrations, ranging between 2.5 and $100 \mu \mathrm{g}$ per extract,(ODsample). After 20 min of incubation in the dark the absorbance was monitored at $517 \mathrm{~nm}$ on a Hitachi U-1900 radio beam spectrophotometer (serial no. 2023-029; Hitachi). $\mathrm{MeOH}$ was used as a blank and DPPH alone in $\mathrm{MeOH}$ was used as the control (ODcontrol). The percentage RSC of the tested extracts was calculated using the equation: $\mathrm{RCS} \%=($ ODcontrol-ODsampleODcontrol $) \times 100$.

ABTS $^{\bullet+}$ radical scavenging assay. The ABTS ${ }^{\bullet+} \mathrm{RSC}$ of the tested extracts was determined as previously described by Cano et al (16), with minor modifications (14). Briefly, $1 \mathrm{ml}$ of the reaction mixture containing ABTS $^{\cdot+}(1 \mathrm{mM}), \mathrm{H}_{2} \mathrm{O}_{2}$ $(30 \mu \mathrm{M})$ and horseradish peroxidase $(6 \mu \mathrm{M})$ in $50 \mathrm{mM}$ PBS $(\mathrm{pH}=7.5)$ was prepared in distilled water $\left(\mathrm{dH}_{2} \mathrm{O}\right)$. Following incubation for $45 \mathrm{~min}$ in the dark, $10 \mu \mathrm{l}$ of the tested extracts, at various concentrations, ranging from 2.5 to $50 \mu \mathrm{g}$ per extract, was added (ODsample) and the absorbance at $730 \mathrm{~nm}$ was read on a Hitachi U-1900 radio beam spectrophotometer (serial no. 2023-029; Hitachi). In each experiment, a blank without the peroxidase was used, while the $\mathrm{ABTS}^{-+}$radical solution without the extract was used as the control (ODcontrol). The RSC percentage was determined using the same equation as that described for the DPPH assay.

Evaluation of the antimutagenic capacity of the extracts using the Ames test. To evaluate the antimutagenic capacity of the tested extracts we applied the Ames test using the bacterium strain Salmonella typhimurium TA102 (MolTox) according to Maron and Ames (17). In brief, $700 \mu \mathrm{l}$ of the bacterium culture were used to inoculate $30 \mathrm{ml}$ of autoclaved Oxoid nutrient broth no. 2 . The cultures were placed on a vibrator (100 rpm) and incubated in the dark at $37^{\circ} \mathrm{C}$ until the cells reached a density of $1-2 \times 10^{9}$ colony forming units $(\mathrm{CFU} / \mathrm{ml}$, $\mathrm{OD}_{540}$ between 0.1 and 0.2 ). The following substances were then added in the sterile tubes: Plates with oxidant + the tested compound; $2 \mathrm{ml}$ of top agar, $100 \mu \mathrm{l}$ of the bacterial culture, $50 \mu \mathrm{l}$ of tert-butyl hydroperoxide $(0.4 \mathrm{mM})$ and $50 \mu \mathrm{l}$ of each extract at various concentrations, ranging from 2 to $32 \mu \mathrm{g}$ per extract/plate. In addition, a plate with the oxidizing agent alone and a plate without the oxidizing agent or the tested compound were used as positive and negative controls. Moreover, each extract was examined at the two highest concentrations used in the assay for putative induction of mutations. The aforementioned tubes were poured onto plates covered by glucose minimal agar and incubated at $37 \pm 2{ }^{\circ} \mathrm{C}$ for $48 \mathrm{~h}$. Then, the histidine revertant colonies (His+) were counted. The number of induced revertants was obtained by subtracting the number of spontaneous revertants from the number of revertants on the plates with the mutagen and/or antioxidant. The percentage inhibition of mutagenicity was calculated as: inhibition $=$ no . of colonies per plate with oxidant + tested compound number of colonies per plate with oxidant alone x100.

Evaluation of the antigenotoxicity of the extracts using the DNA relaxation assay. The DNA relaxation assay has been previously described (18). The principle of this assay is dependent on the conformational changes of the plasmid (pBluescript-SK+, Fermentas) DNA, which natively exists in the supercoiled conformation but after a single-strand break is converted to an open circular one. Based on this, the protective activity of the olive blossom extracts against DNA single-strand breaks by 2,2'-azobis AAPH $(2.5 \mathrm{mM})$ were assessed. Specifically, in a total reaction volume of $10 \mu \mathrm{l}, 2 \mu \mathrm{l}$ of DNA $(4 \mu \mathrm{g} / \mathrm{ml})$ was mixed with PBS, AAPH and different concentrations of the tested extracts ranging between 1 and $300 \mu \mathrm{g} / \mathrm{ml}$ and the mixture was incubated at $37^{\circ} \mathrm{C}$ for $45 \mathrm{~min}$. For each assay, a negative control (DNA without the tested compounds and AAPH) and a positive control (DNA with AAPH and without the tested compounds) were used. Moreover, the maximum tested concentrations were mixed alone with DNA for possible induction of DNA strand breaks. However, none of the tested concentrations were found to induce DNA breaks. Subsequently, $3 \mu \mathrm{l}$ of loading buffer (bromophenol blue $0.25 \%+30 \%$ glycerol) was added and the samples were loaded on a $0.8 \%$ agarose gel, following electrophoresis at $70 \mathrm{~V}$ for $60 \mathrm{~min}$. Eventually, the gel was stained with $12.5 \mu \mathrm{l}$ of ethidium bromide $(10 \mathrm{mg} / \mathrm{ml})$ in $250 \mathrm{ml}$ of $\mathrm{dH}_{2} \mathrm{O}$ for $30 \mathrm{~min}$, and then washed with $250 \mathrm{ml}$ of $\mathrm{dH}_{2} \mathrm{O}$ for another $30 \mathrm{~min}$. Finally, the gel was exposed to UV, the MultiImage Light Cabinet (Alpha Innotech) was used to capture the gel images and the results were analyzed with the Alpha View suite.

Cell culture experiment. According to the international guidelines on good cell culture practice (19), the cell lines used in this research were checked for mycoplasma, using PCR. According to PCR results the tested cell lines, were mycoplasma free. Furthermore, a morphology check, both at high and low culture densities via microscope were conducted to authenticate the state of cells, through their phenotypic 
A


B



Figure 1. (A) HPLC chromatograms of the tested hydroalcoholic extracts (AGRI, KTKT, EKPA and ANKT) at $254 \mathrm{~nm}$ (upper line), 280 nm (middle line) and $365 \mathrm{~nm}$ (lower line). Compounds: 1, secoiridoid derivative; 2, quercetin-3-O-sophoroside; 3, secoiridoid derivative; 4, rutin; 5, flavonoid derivative; 6, oleuropein. (B) Related quantification analysis of the major components of olive flower extracts using HPLC at 254 nm. Peak 1, secoiridoid derivative; Peak 2, quercetin-3-O-sophoroside; Peak 3, secoiridoid derivative; Peak 4, rutin; Peak 5, flavonoid derivative; Peak 6, oleuropein HPLC, high-performance liquid chromatography.

characteristics. Finally, the passage number for each cell line did not exceed the 30 population doublings.

Cell culture conditions. The cervical cancer (HeLa), murine myoblasts $(\mathrm{C} 2 \mathrm{C} 12)$ and the liver cancer (HepG2) cells were cultured at $37^{\circ} \mathrm{C}$ in $5 \% \mathrm{CO}_{2}$ in Dulbecco's modified Eagle's medium (DMEM) containing fetal bovine serum (FBS) $(10 \% \mathrm{v} / \mathrm{v})$, L-glutamine $(2 \mathrm{mM})$, penicillin $(100 \mathrm{U} / \mathrm{ml})$ and streptomycin $(100 \mathrm{U} / \mathrm{ml})$. The endothelial cells (EA.hy926) were cultured at $37^{\circ} \mathrm{C}$ in $5 \% \mathrm{CO}_{2}$ in DMEM containing FBS $(10 \% \mathrm{v} / \mathrm{v})$, HEPES $(25 \mathrm{mM})$, L-glutamine $(2 \mathrm{mM})$, penicillin $(100 \mathrm{U} / \mathrm{ml})$ and streptomycin $(100 \mathrm{U} / \mathrm{ml})$.

HeLa and HepG2 cell lines were donated by Assistant Professor Kalliopi Liadaki (Department of Biochemistry and Biotechnology, University of Thessaly, Larissa, Greece). The C2C12 myoblasts were donated by Professor Koutsilieris (National and Kapodistrian University of Athens, Athens, Greece). Finally, the EA.hy926 cells were donated by Professor Koukoulis (University Hospital of Thessaly, Larissa, Greece).
Cell viability assay. The working concentrations of the tested extracts did not induce cytotoxicity in any cell line. In order to check which concentrations of the extracts were cytotoxic (i.e., which of them compromised cell viability) the XTT assay kit was used, according to the manufacturer's protocol.

Treatment of the cell lines with the extracts. The cells of each cell line were incubated in culture medium in flasks $\left(25 \mathrm{~m}^{2}\right)$ for $24 \mathrm{~h}$. The medium was then removed and serum-free medium containing the tested extracts at non-cytotoxic concentrations was re-added in the flasks. The treatment of the cells with the extracts (or with the serum-free medium only for the control cells) lasted $24 \mathrm{~h}$. Subsequently, they were trypsinised, collected, centrifuged $\left(300 \mathrm{x} \mathrm{g}, 10 \mathrm{~min}, 5^{\circ} \mathrm{C}\right)$ and the supernatant fluid was discarded. The cellular pellet was re-suspended in PBS.

Measurement of endogenous GSH and ROS levels in cell lines using flow cytometry. The intracellular GSH and ROS levels were assessed using the fluorescent dyes mercury orange 
Table I. $\mathrm{IC}_{50}$ values of the extracts in the $\mathrm{DPPH}^{*}$ and $\mathrm{ABTS}^{*+}$ assays and their total phenolic content (TPC) expressed as $\mathrm{mg}$ of Gallic Acid (GA) equivalent per $g$ of extract.

\begin{tabular}{lcrrcc}
\hline & \multicolumn{1}{c}{$\mathrm{DPPH}^{\bullet}$} & \multicolumn{1}{c}{$\mathrm{ABTS}^{\circ+}$} & & TPC \\
\cline { 2 - 3 } \cline { 5 - 5 } Extracts & $\mathrm{IC}_{50}(\mu \mathrm{g} / \mathrm{ml})$ & \multicolumn{1}{c}{$\mathrm{IC}_{50}(\mu \mathrm{g} / \mathrm{ml})$} & & $\mathrm{mgGA} / \mathrm{g}$ extract \\
\hline AGRI & $40.50 \pm 2.66^{\mathrm{a}}$ & $9.25 \pm 0.78^{\mathrm{a}}$ & & 81.03 \\
KTKT & $73.25 \pm 1.29^{\mathrm{b}}$ & $15.77 \pm 0.23^{\mathrm{b}}$ & & 50.92 \\
EKPA & $50.75 \pm 2.16^{\mathrm{a}}$ & $32.88 \pm 0.19^{\mathrm{c}}$ & & 76.15 \\
ANKT & $73.25 \pm 1.49^{\mathrm{b}}$ & $23.06 \pm 0.19^{\mathrm{d}}$ & & 66.06 \\
\hline
\end{tabular}

${ }^{\mathrm{a}-\mathrm{d}}$ Means without a common letter are significantly different $(\mathrm{n}=3)$ $(\mathrm{P}<0.05)$.

and DCF-DA, respectively (20). A $400 \mu \mathrm{M}$ stock solution of mercury orange was prepared in acetone and a $400 \mu \mathrm{M}$ stock solution of DCF-DA was prepared in $\mathrm{MeOH}$. The cell pellet was resuspended in PBS at the concentration of $1 \times 10^{6}$ cells $/ \mathrm{ml}$ and incubated with mercury orange $(40 \mu \mathrm{M})$ or DCF-DA $(10 \mu \mathrm{M})$ at $37^{\circ} \mathrm{C}$ for $30 \mathrm{~min}$. The cells were then washed and re-suspended in PBS and subjected to analysis using a FACSCalibur flow cytometer (BD Biosciences) with excitation and emission wavelengths at 488 and $530 \mathrm{~nm}$ for ROS and at 488 and $580 \mathrm{~nm}$ for GSH. The cells were analyzed at a flow rate of 1,000 events/sec. Analyses were performed on 10,000 cells per sample and the fluorescence intensities were measured on a logarithmic scale. Data were analyzed using BD Cell Quest software (BD Biosciences).

Statistical analysis. SPSS version 21.0 was used (SPSS Inc., Chicago, IL, USA) for data analysis. All data were analyzed using one-way ANOVA followed by Tukey's test for multiple pair wise comparisons. Each experiment was repeated at least 3 times. Data are presented as mean \pm standard error of the mean (SEM). The significance level was set at $\mathrm{P}<0.05$, and the subset of alpha level was at 0.05 . A bivariate Spearman's correlation was conducted to correlate the total polyphenolic content (TPC) of the extracts with the four assays tested, DPPH, ABTS, plasmid relaxation assay and Ames test.

\section{Results}

HPLC analysis. The qualitative HPLC analysis of the olive flower hydroalcoholic extracts revealed that the major compounds belong in two chemical categories, secoiridoid derivatives and flavonoid derivatives (Fig. 1). Of these, quercetin-3-O-sophoroside (peak 2, Fig.1A) and oleuropein (peak 6, Fig.1A) are the main representatives of each category. The comparison study of the extracts showed a high similarity of the chemical composition of AGRI, EKPA and ANKT samples and only small differences on the quantities of the major compounds were observed. On the other hand, KTKT sample appeared to be poorer in terms of chemical composition while the main compounds, quercetin-3-O-sophoroside and oleuropein were present in small quantities. In more detail, the related quantification analysis revealed that all extracts
Table II. Antigenotoxic and antimutagenic activity of the tested extracts. ${ }^{a}$

\begin{tabular}{|c|c|c|}
\hline & Plasmid relaxation assay & Ames test \\
\hline Extracts & $\mathrm{IC}_{50}(\mu \mathrm{g} / \mu \mathrm{l})$ & $\mathrm{IC}_{50} \mu \mathrm{g}$ extract $/$ plate \\
\hline AGRI & $1.717 \pm 0.27^{\mathrm{b}}$ & $3.33 \pm 0.30^{\mathrm{b}}$ \\
\hline KTKT & $8.233 \pm 9.62^{\mathrm{c}}$ & $4.11 \pm 0.09^{c}$ \\
\hline EKPA & $2.850 \pm 9.62^{\mathrm{b}}$ & $3.09 \pm 0.2^{\mathrm{b}}$ \\
\hline ANKT & $2.117 \pm 2.24^{b}$ & $2.79 \pm 0.17^{\mathrm{b}}$ \\
\hline
\end{tabular}

${ }^{a}$ As assessed by the plasmid relaxation assay and the Ames test, respectively. ${ }^{b, c}$ Means without a common letter are significantly different $(\mathrm{n}=3)(\mathrm{P}<0.05)$.

Table III. Amounts where the tested extracts exhibited cytotoxicity, as assessed by the XTT assay.

\begin{tabular}{lcc}
\hline Cell lines & Extracts & $\begin{array}{c}\text { Cytotoxic amount } \\
(\mu \mathrm{g} / \mathrm{ml})\end{array}$ \\
\hline EA.hy926 & AGRI & 10 \\
& KTKT & 25 \\
& EKPA & 50 \\
C2C12 & ANKT & 100 \\
& AGRI & 70 \\
& KTKT & 60 \\
& EKPA & 100 \\
HeLa & ANKT & 25 \\
& AGRI & 50 \\
& KTKT & 100 \\
HepG2 & EKPA & 25 \\
& ANKT & 100 \\
& AGRI & 10 \\
& KTKT & 100 \\
& EKPA & 25 \\
& ANKT & 100 \\
\hline
\end{tabular}

contain similar concentration of the compound 1 (peak 1) in contrast to other compounds where significant variations were observed between the different extracts (Fig. 1B). Regarding the quercetin-3-O-sophoroside, AGRI extract contains the highest amount similar to EKPA and ANKT extracts while KTKT contains significantly lower levels than the other three extracts. By contrast, oleuropein was found in greater quantities in the EKPA extract followed by AGRI extract (similar concentration) and ANKT while KTKT contains low amount of oleuropein (Fig. 1B).

$I C_{50}$ values of the extracts in the $\mathrm{DPPH}$ and $\mathrm{ABTS}^{\circ+}$ assays and total phenolic content (TPC) measurement. As indicated by the results regarding the $\mathrm{DPPH}^{*}$ and $\mathrm{ABTS}^{*+}$ assays, all the extracts exhibited antioxidant activity. Specifically, regarding the $\mathrm{DPPH}^{\bullet}$ assay the $\mathrm{IC}_{50}$ values of AGRI, KTKT, EKPA and 

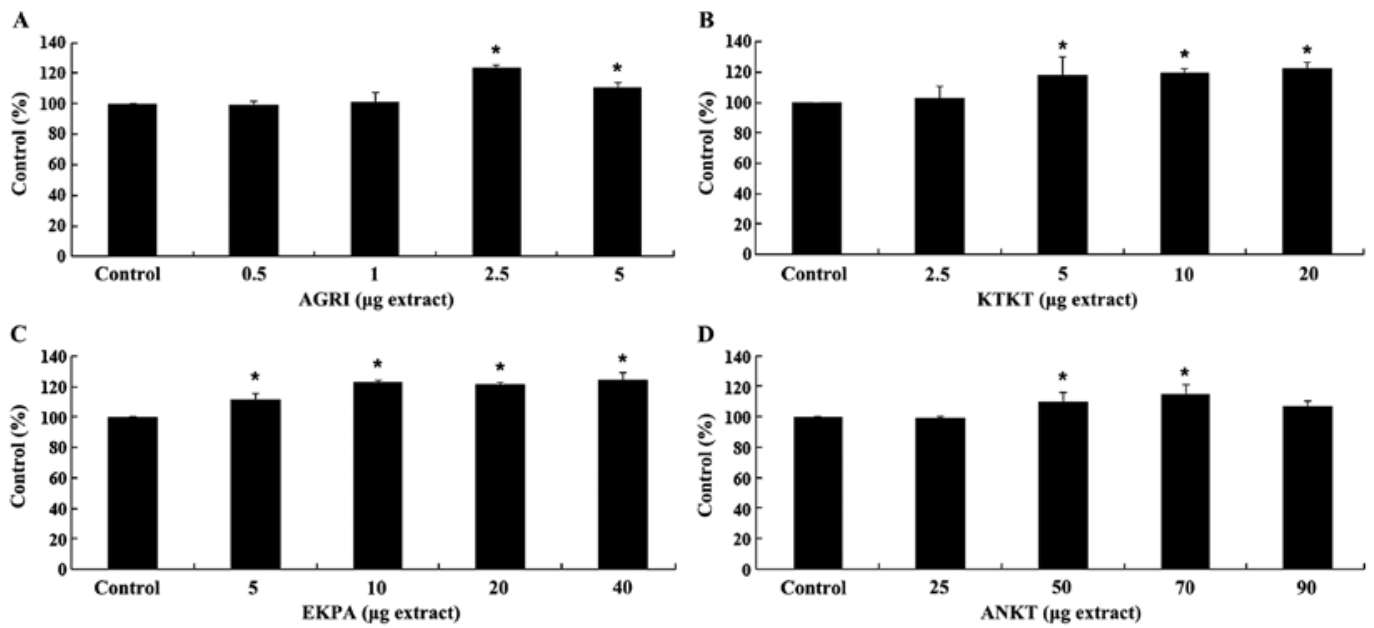

Figure 2. Effects of the tested extracts on GSH levels of EA.hy926 cells after $24 \mathrm{~h}$ of incubation. (A) AGRI. (B) KTKT. (C) EKPA. (D) ANKT. Bar charts showing the GSH levels, as calculated by BD Cell Quest software. All results are expressed as the means \pm SEM of 4 experiments $(n=4)$. "Statistically significant difference between blossom extracts and the control. GSH, reduced form of glutathione.
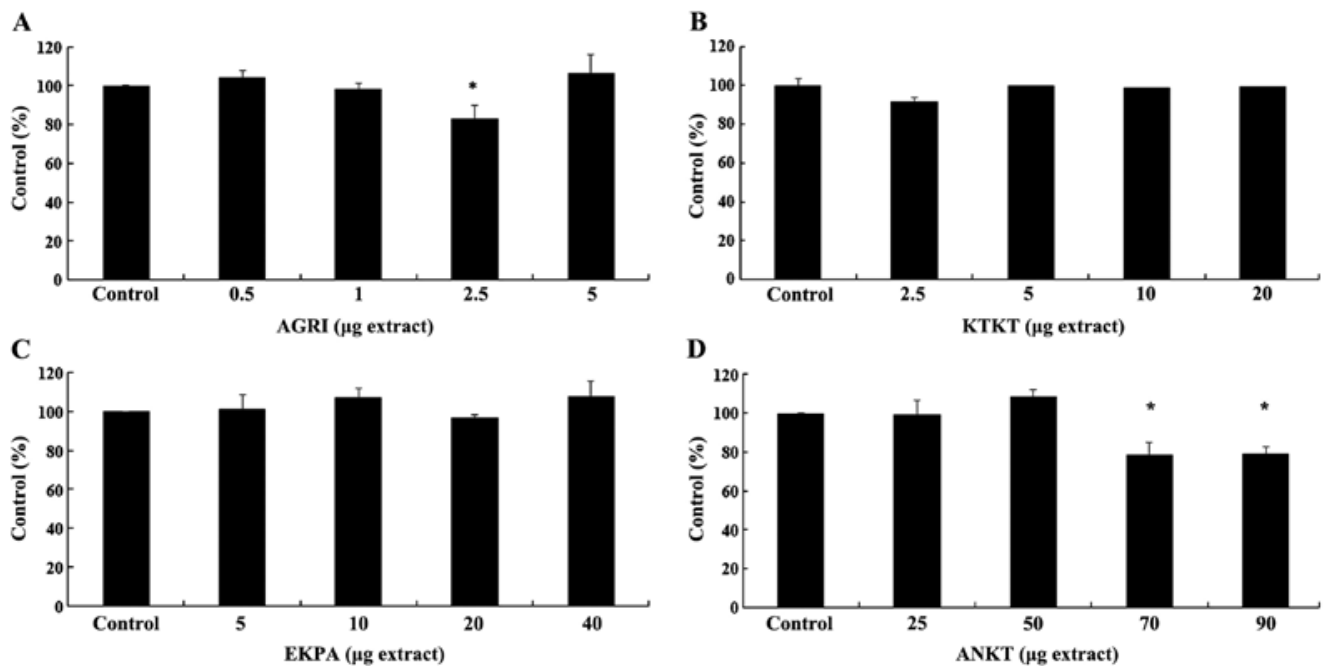

Figure 3. Effects of the tested extracts on ROS levels of EA.hy926 cells after $24 \mathrm{~h}$ of incubation. (A) AGRI. (B) KTKT. (C) EKPA. (D) ANKT. Bar charts showing the ROS levels, as calculated by BD Cell Quest software. All results are expressed as the means \pm SEM of 4 experiments (n=4). "Statistically significant difference between blossom extracts and the control. ROS, reactive oxygen species.


Figure 4. Effects of the tested extracts on GSH levels of C2C12 cells after $24 \mathrm{~h}$ of incubation. (A) AGRI. (B) KTKT. (C) EKPA. (D) ANKT. Bar charts showing the GSH levels, as calculated by BD Cell Quest software. Results are expressed as the means \pm SEM of 4 experiments ( $n=4)$. "Statistically significant difference between blossom extracts and the control. GSH, reduced form of glutathione. 

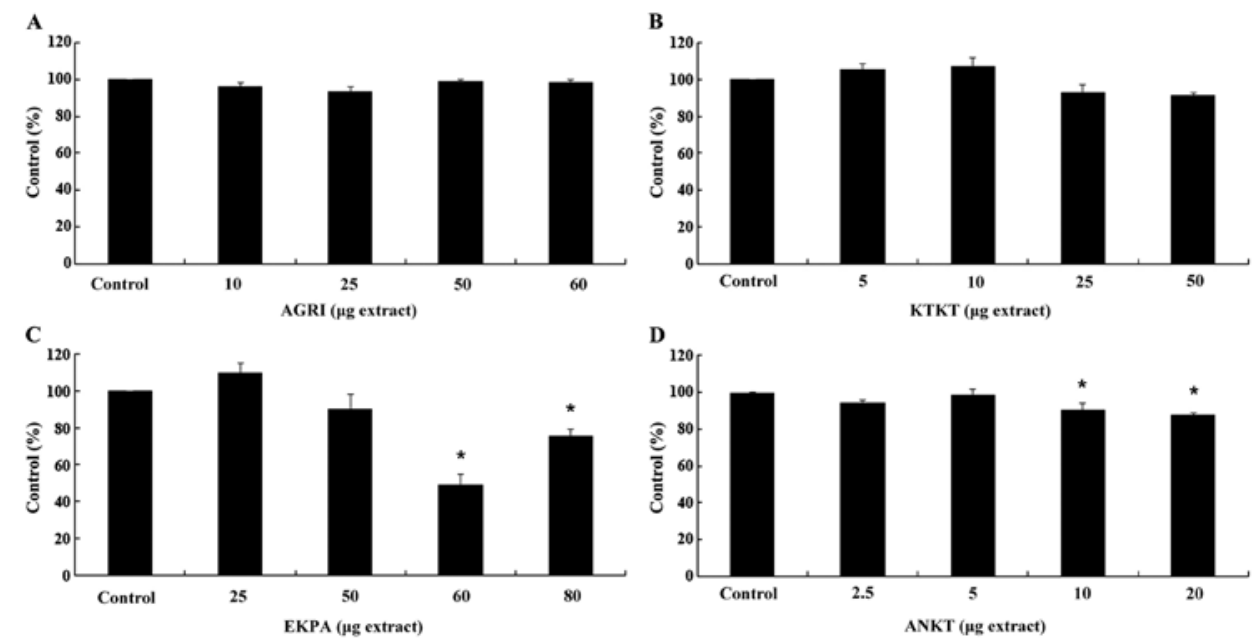

Figure 5. Effects of the tested extracts on ROS levels of C2C12 cells after $24 \mathrm{~h}$ of incubation. (A) AGRI. (B) KTKT. (C) EKPA. (D) ANKT. Bar charts showing the ROS levels, as calculated by BD Cell Quest software. All results are expressed as the means \pm SEM of 4 experiments (n=4). "Statistically significant difference between blossom extracts and the control. ROS, reactive oxygen species.
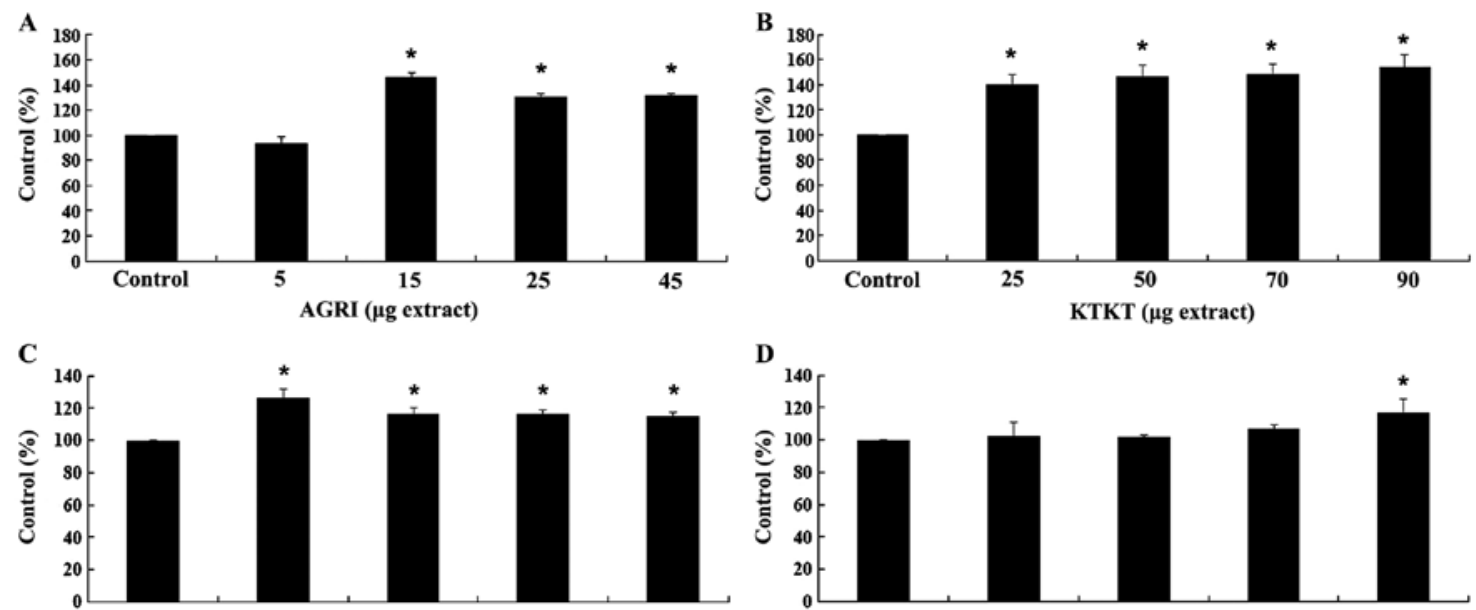

Figure 6. Effects of the tested extracts on GSH levels of HeLa cells after $24 \mathrm{~h}$ of incubation. (A) AGRI. (B) KTKT. (C) EKPA. (D) ANKT. Bar charts showing the GSH levels, as calculated by BD Cell Quest software. All results are expressed as the means \pm SEM of 4 experiments ( $n=4)$. "Statistically significant difference between blossom extracts and the control. GSH, reduced form of glutathione.

ANKT were equal to $40.50,73.25,50.75$ and $73.25 \mu \mathrm{g}$ of extract, respectively (Table I). In detail, statistical analysis revealed that AGRI exerted a stronger antioxidant activity compared with KTKT $(\mathrm{P}=0.002)$ and ANKT $(\mathrm{P}=0.002)$. By contrast, EKPA was more potent than KTKT $(\mathrm{P}=0.003)$ and ANKT $(\mathrm{P}=0.003)$. Moreover, as assessed by the $\mathrm{ABTS}^{\circ+}$ assay the AGRI, KTKT, EKPA and ANKT extracts exhibited $\mathrm{IC}_{50}$ values equal to $9.25,15.77,32.88$ and $23.06 \mu \mathrm{g}$ of extract, respectively (Table I). From the obtained results it seems that all extracts exhibited a statistically significant difference $(\mathrm{P}=0.0001) . \mathrm{IC}_{50}$ values represent the amount of tested compounds required for $50 \%$ reduction of the two radicals. Given that the lower the $\mathrm{IC}_{50}$ value the more powerful antioxidant activity, our results revealed that in both assays AGRI exerted the strongest antioxidant activity, compared with the remaining three (i.e., KTKT, EKPA and ANKT). Total phenolic content was estimated in four olive flower extracts, expressed in $\mathrm{mg}$ of gallic acid/g of extract. Estimated values varied from 50.92 to $81.03 \mathrm{mg}$ of gallic acid/g extract (Table I), showing a significant difference in the phenolic content among the extracts tested. AGRI extract exhibited the highest phenolic content (81.03) followed by EKPA (76.15) and ANKT (66.06) extracts while KTKT exhibited the lowest value (50.92). It is noteworthy that the calculated TPC values of the extracts are in accordance with the corresponding antioxidant capacity expressed by DPPH values.

Antigenotoxic and antimutagenic activity of the tested extracts as assessed by the plasmid relaxation assay and the Ames test. The obtained results from the plasmid relaxation assay revealed that AGRI $(\mathrm{P}=0.003)$, EKPA $(\mathrm{P}=0.019)$ and ANKT $(\mathrm{P}=0.005)$ possess equal antigenotoxic activity and were more prone to protect the plasmid DNA from lesions compared with KTKT (Table II). Specifically, the $\mathrm{IC}_{50}$ values of AGRI, KTKT, EKPA and ANKT were calculated at 1.717, $8.233,2.85$ and $2.17 \mu \mathrm{g} / \mu \mathrm{l}$, respectively. The same pattern was also observed in the Ames test. More specifically, the $\mathrm{IC}_{50}$ values of AGRI, KTKT, EKPA and ANKT were calculated at 

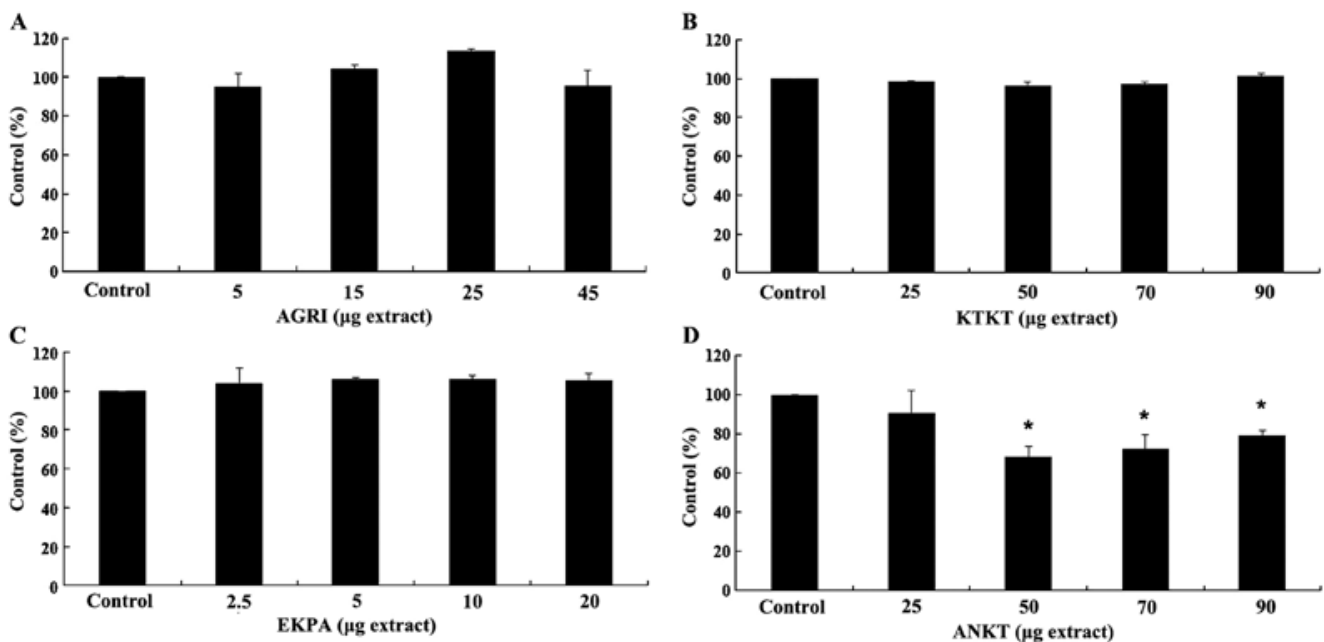

Figure 7. Effects of the tested extracts on ROS levels of HeLa cells after $24 \mathrm{~h}$ of incubation. (A) AGRI. (B) KTKT. (C) EKPA. (D) ANKT. Bar charts showing the ROS levels, as calculated by BD Cell Quest software. All results are expressed as the means \pm SEM of 4 experiments (n=4). *Statistically significant difference between blossom extracts and the control. ROS, reactive oxygen species.


Figure 8. Effects of the tested extracts on GSH levels of HepG2 cells after $24 \mathrm{~h}$ of incubation. (A) AGRI. (B) KTKT. (C) EKPA. (D) ANKT. Bar charts showing the GSH levels, as calculated by BD Cell Quest software. All results are expressed as the means \pm SEM of 4 experiments (n=4). "Statistically significant difference between blossom extracts and the control. GSH, reduced form of glutathione.
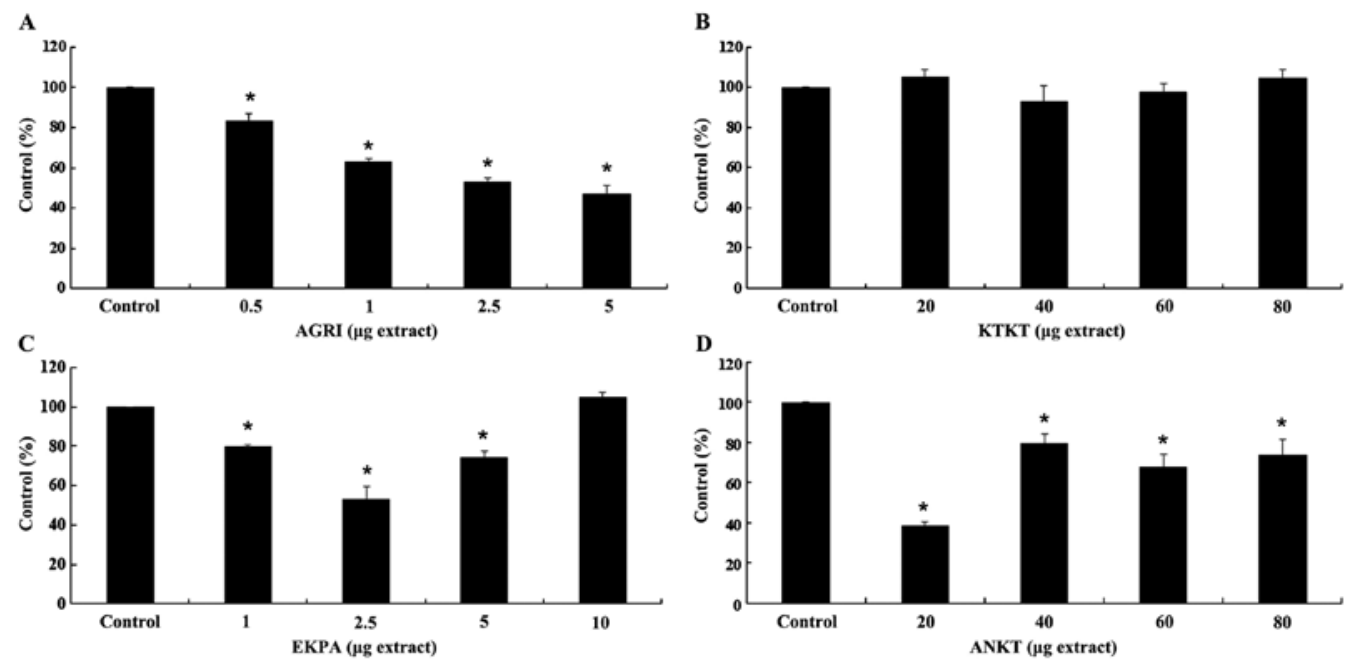

Figure 9. Effects of the tested extracts on ROS levels of HepG2 cells after $24 \mathrm{~h}$ of incubation. (A) AGRI. (B) KTKT. (C) EKPA. (D) ANKT. Bar charts showing the ROS levels, as calculated by BD Cell Quest software. All results are expressed as the means \pm SEM of 4 experiments ( $=4$ ). "Statistically significant difference between blossom extracts and the control. ROS, reactive oxygen species. 
3.33, 4.11, 3.09 and $2.79 \mu \mathrm{g}$ of extract, respectively (Table II). Thus, AGRI $(\mathrm{P}=0.043)$, EKPA $(\mathrm{P}=0.011)$ and ANKT $(\mathrm{P}=0.002)$ possess equal antimutagenic activity compared with KTKT.

Amounts where the tested extracts exhibited cytotoxicity as assessed by the XTT assay. The antioxidant capacity of the tested extracts was measured in four cell lines: EA.hy926, HeLa, and HepG2 cells, as well as C2C12 myoblasts. Prior to examining the potential antioxidant activity of the olive blossom extracts in cell culture, the concentration threshold above which the tested compounds exhibited cytotoxic effects in the cell lines was investigated. A range of amounts for each extract between 1.0 and $100.0 \mu \mathrm{g}$ of extract was administered to the cells. The results from the XTT assay indicated that AGRI was more cytotoxic in EA.hy926 and HepG2 cells, exhibiting cytotoxicity at $10 \mu \mathrm{g}$ of extract. Additionally, ANKT exhibited cytotoxicity at $25.0 \mu \mathrm{g}$ in $\mathrm{C} 2 \mathrm{C} 12$ myoblasts. Finally, the cytotoxicity level was observed at $25.0 \mu \mathrm{g}$ for EKPA in HeLa cells (Table III). The obtained results revealed a tissue-specific activity of the extracts. Moreover, EA.hy926 seems to be the most sensitive cell line compared to the remaining cell lines, since the majority of the extracts induced cytotoxicity at low concentrations.

GHS and ROS levels in EA.hy926 cells. The results obtained from flow cytometry revealed that all tested extracts significantly increased GSH levels compared with the control in the four cell lines (Figs. 2, 4, 6 and 8). However, the corresponding ROS levels were not uniformly accompanied by statistical alterations (Figs. 3, 5, 7 and 9). Specifically, the AGRI increased the GSH levels of the EA.hy 926 cells by 24 and $11 \%$ at 2.5 and $5 \mu \mathrm{g}$ of extract, respectively, compared with the control (Fig. 2A). The ROS levels were decreased by $17 \%$ at $2.5 \mu \mathrm{g}$ AGRI, compared with control (Fig. 3A). The KTKT extract also increased GSH levels by 18, 20 and $23 \%$ at 5, 10 and $20 \mu \mathrm{g}$ of extract (Fig. 2B), respectively, while there was no alteration at ROS levels (Fig. 3B). Additionally, the GSH levels due to the EKPA extract were elevated by 12, 24, 22 and $25 \%$ at 5, 10, 20 and $40 \mu \mathrm{g}$ of extract (Fig. 2C), with no alterations at ROS levels (Fig. 3C). Finally, ANKT increased GSH levels by 11 and $16 \%$ at 50 and $70 \mu \mathrm{g}$ of extract, respectively (Fig. 2D) with a concomitant decrease at ROS levels by $21 \%$ at 70 and $90 \mu$ g (Fig. 3D).

GHS and ROS levels in C2C12 cells. According to the obtained results from flow cytometry in $\mathrm{C} 2 \mathrm{C} 12$, GSH levels were elevated after $24 \mathrm{~h}$ incubation with AGRI by 40, 50, 18 and $13 \%$ at $10,25,50$ and $60 \mu \mathrm{g}$ of extract, respectively, compared with the control (Fig. 4A), while, ROS levels remained unaffected (Fig. 5A). Moreover, KTKT increased GSH levels by 70,99 and $22 \%$ at 10,25 and $50 \mu \mathrm{g}$ of extract, respectively, compared with control (Fig. 4B) with no effect on ROS levels (Fig. 5B). Additionally, EKPA increased GSH by 21, 46 and $37 \%$ at 50, 60 and $80 \mu \mathrm{g}$ of extract, respectively (Fig. 4C) with a concomitant reduction at ROS levels by 51 and $24 \%$ at 60 and $80 \mu \mathrm{g}$ of EKPA, respectively, compared with control (Fig. 5C). Finally, ANKT also increased GSH levels by 14 , 38,39 and $44 \%$ at $2.5,5,10$ and $20 \mu \mathrm{g}$ of extract, respectively, compared with control (Fig. 4D) and decreased ROS levels by 10 and $12 \%$ at 10 and $20 \mu \mathrm{g}$ of extract (Fig. 5D).
GHS and ROS levels in HeLa cells. Furthermore, after AGRI administration of HeLa cells, GSH levels were increased by 46,31 and $32 \%$ at 15,25 and $45 \mu \mathrm{g}$ of extract compared with control, respectively (Fig. 6A), while ROS levels remained relatively unaffected (Fig. 7A). Additionally, KTKT increased GSH by $41,47,49$ and $55 \%$ at $25,50,70$ and $90 \mu \mathrm{g}$ of extract, respectively (Fig. 6B). By contrast, ROS levels were not altered (Fig. 7B). A mild increase at GSH levels was also observed after EKPA administration for $24 \mathrm{~h}$, by $27,17,17$ and $15 \%$ at $2.5,5,10$ and $20 \mu \mathrm{g}$ of extract, respectively (Fig. 6C) with no effects on ROS levels (Fig. 7C). Additionally, ANKT administration increased GSH by $17 \%$ at $90 \mu \mathrm{g}$ of extract compared with control (Fig. 6D). By contrast, ROS levels were decreased by 32,28 and $20 \%$ at 50,70 and $90 \mu \mathrm{g}$ of ANKT, respectively (Fig. 7D).

GHS and ROS levels in HepG2 cells. Finally, with respect to the effects on HepG2 cells (Fig. 8), AGRI, increased GSH levels by 10,31 and $19 \%$ at $0.5,1$ and $2.5 \mu \mathrm{g}$ of extract compared with control, respectively. Nevertheless, at $5 \mu \mathrm{g}$ of AGRI, GSH levels were decreased by $12 \%$ indicating a pro-oxidant effect (Fig. 8A). Additionally, ROS levels were decreased by 16, 37, 47 and $53 \%$ after administration of $0.5,1,2.5$ and $5 \mu \mathrm{g}$ of AGRI, respectively (Fig. 9A). Moreover, GSH levels were increased by 31 and $17 \%$ at 40 and $60 \mu \mathrm{g}$ of KTKT, respectively. However, at $80 \mu \mathrm{g}$ of KTKT GSH levels were decreased by $32 \%$, also indicating a pro-oxidant effect (Fig. 8B). Unlike GSH, ROS levels were not significantly affected (Fig. 9B). Furthermore, EKPA increased GSH levels at all tested concentrations. In detail, after administration of 1, 2.5, 5 and $10 \mu \mathrm{g}$ of EKPA GSH levels were increased by $32,65,57$ and $46 \%$ compared with control, respectively (Fig. 8C). EKPA administration was accompanied by ROS decrease by 20,47 and $26 \%$ at 1 , 2.5 and $5 \mu \mathrm{g}$ of extract, respectively (Fig. 9C). Additionally, ANKT increased GSH levels by 11 and $20 \%$ at 60 and $80 \mu \mathrm{g}$ of extract, respectively (Fig. 8D), whereas ROS levels were decreased by $62,20,32$ and $26 \%$ at $20,40,60$ and $80 \mu \mathrm{g}$ of ANKT compared with control, respectively (Fig. 9D).

\section{Discussion}

In the present study, we evaluated the antioxidant, antimutagenic and antigenotoxic effects of four polyphenolic olive blossom extracts in vitro and in cell culture. Our results show that all the tested extracts exert a great antioxidant capacity as assessed by scavenging free radicals (DPPH $\left.{ }^{*}, \mathrm{ABTS}^{\circ+}\right)$. In addition, they showed antimutagenic and antigenotoxic activity and they also have the ability to increase the endogenous GSH levels with a concomitant decrease in the endogenous ROS concentration in general. It is worth mentioning that $20 \%$ of olive tree flowers set a mature fruit, whereas the remaining $80 \%$ fall onto the ground without any benefit. It is known from the literature, and verified from our qualitative HPLC analysis (Fig. 1) that, olive flowers contain a large number of bioactive compounds that may be of benefit to human health (21). Thus, the potential exploitation of olive blossoms due to their bioactive role could offer great financial support to producers. Furthermore, they are considered as sources for natural pharmaceutical products minimizing the need for industrial production of chemical compounds. 
All extracts exhibited antioxidant activity, which depicted a correlation between phenol content and DPPH and ABTS ${ }^{\cdot+}$ radicals scavenging activity (Table $\mathrm{I}$ ). The $\mathrm{IC}_{50}$ values of the olive flower extracts ranged from 40.50 to $73.25 \mu \mathrm{g}$ of extract for the DPPH assay and between 9.25 and $32.88 \mu \mathrm{g}$ of extract for the $\mathrm{ABTS}^{\cdot+}$ assay. AGRI possessed the lower $\mathrm{IC}_{50}$ value in the two methods indicating that it is the most potent between the tested extracts. This is probably due to the high concentration of phenols and mainly Oleuropein and flavonoid glucosides (Quercetin-3-O-sophoroside). In previous studies, olive flower extracts exhibited a strong antioxidant potential as assessed by the $\mathrm{DPPH}^{\bullet}$ and $\mathrm{ABTS}^{-+}$assays $(6,11)$. The lower $\mathrm{IC}_{50}$ values were observed in the samples harvested in the last developmental stage of the flower (August), thus, it seems that the antioxidant activity was increased according to the developmental stage (6). Furthermore, DPPH' scavenging capacity of different olive tree parts was found to be higher than that of synthetic antioxidant butylated hydroxytoluene (BHT) [89.16\% inhibition of DPPH radical (22)], suggesting the existence of specific bioactive compounds. Specifically, the percentage of inhibition of the free radical DPPH ${ }^{*}$ was between 93.75-95.22\% for leaves and 95.43-96.06\% for fruits $(23,44)$. In addition, the percentage of inhibition of the free radical ABTS $^{\bullet+}$ ranged between $91.97-92.42 \%$ for stems, $58.38-74.55 \%$ for fruits, while the same scavenging ability was observed for the leaves. However, the extracts from olive leaves possessed the highest antioxidant capacity compared to stems and fruits (23). Moreover, our previous studies indicated that the antioxidant capacity of biophenolic extracts derived from different olive oils depicted $\mathrm{IC}_{50}$ values of $9.25-49.45 \mu \mathrm{g} / \mathrm{ml}$ indicating the significance of the different biophenolic composition on free radical scavenging activity of the extracts $(25,26)$. The aforementioned data indicate the heterogeneous presence of bioactive compounds between olive tree parts and, therefore, the variability of their antioxidant capacities (23). The antioxidant activity and the amount of total phenols present in the extracts suggest that their RSC can be attributed to the hydroxylated phenolic compounds and in particular, to the number of hydroxyl substituents in the aromatic ring, the nature of the substituents at the para or ortho position (27), as well as to the availability of phenolic hydrogens (28). These compounds react with free radicals formed through the autoxidation process, giving rise to a newborn radical, which is stabilized by the resonance effect of the aromatic core. Moreover, the synergism between the antioxidants in the mixture render the antioxidant capacity dependent both on the concentration and the interaction between the antioxidants and the structure (6).

The results obtained from the plasmid relaxation assay, which assessed the protective effect of extracts against the ROO•-induced single-stranded DNA fragments showed that AGRI, ANKT and EKPA extracts had statistically significant greater ability to protect DNA fragmentation, compared to KTKT extract, exhibiting an $\mathrm{IC}_{50}$ at $1.717,2.117$ and $2.850 \mu \mathrm{g}$, respectively, while KTKT depicted an $\mathrm{IC}_{50}$ at $82.33 \mu \mathrm{g}$. AGRI also showed the lowest $\mathrm{IC}_{50}$ value in this test. In comparison with other studies, biophenolic extracts derived from olive oils had the ability to protect DNA from lesions at $1.4-82.3 \mu \mathrm{g}$ extract per assay (or $0.14-8.23 \mu \mathrm{g} / \mu \mathrm{l}$ ) as assessed with the plasmid relaxation assay (26). Moreover, the antimutagenic activity of coffee polyphenols exhibited $\mathrm{IC}_{50}$ values of 51.03-
$132.29 \mu \mathrm{g} / \mathrm{ml}$ (29). According to the literature, olive and wild olive polyphenolic extracts possess potent anticancer properties. Specifically, wild olive extracts lead to the reduction of liver carcinoma biomarkers (30). By contrast, olive leaf extracts inhibit the growth and differentiation of leukemia cancer cells (31). It has also been shown that olive polyphenols reduce cell proliferation, invasiveness and tumor growth in cell models of breast cancer (32). Furthermore, olive oil polyphenolic extracts with different polyphenolic composition, in terms of HT and tyrosol (T) had the ability to protect DNA damages induced by ROO*, where the HT-rich ones had greater antigenotoxic activity (i.e., lower $\mathrm{IC}_{50}$ values) (26). In line with our findings, numerous studies have reported that olive oil and the by-products derived from its generation possess both antioxidant and anticancer properties $(4,11,20,25,33-37)$. For example, wild leaf extracts promoted the apoptosis of colon cancer cells (36). In addition, daily consumption of olive oil appeared to alleviate the detrimental effects of oxidative stress in DNA stability (37). Extracts from different parts of olive trees, including flowers, had great antioxidant, antibacterial and antiallergic abilities (11). It is noteworthy that the composition of olive leaf extracts is similar to that of olive oil (34) and of flower extracts containing polyphenols such as HT, T and oleuropein $(6,31)$.

The results from the test of mutagenicity (i.e., the Ames test) showed that AGRI, EKRA and ANKT extracts have a similar capacity to protect plasmid DNA from mutations with an $\mathrm{IC}_{50}$ at $3 \mu \mathrm{g} /$ well while KTKT depicted $\mathrm{IC}_{50}$ at $4 \mu \mathrm{g} /$ well. The results may be explained due to the time of harvesting of the olive blossoms. Although olive flowers KTKT and ANKT belong to the same variety (Lianolia) from the same region, the difference in collection time (5-6/5 and 14-15/5, respectively) resulted in different chemical content of the hydroalcoholic extracts (Fig. 1A) and thus in different biological activity of the extracts. Our results are in agreement with other relevant studies, according to which polyphenols from natural plant extracts, such as coffee (29), pomegranate (38) and olives (39) possess strong antimutagenic activities. According to Spearman's correlation, a statistically significant $(\mathrm{p}<0.05)$ correlation between Folin-Ciocalteu and DPPH was found. Furthermore, the differences in the extract activities may be due to their chemical composition, as assessed by the related quantification analysis (Fig. 1B). It seems that KTKT possesses less amount of querqetin 3-O-sophoroside, oleuropein, secoiridoid derivatives, rutin and flavonoid derivatives. Additionally, Folin-Ciocalteu indicated that it contains the lowest polyphenolic content, thus being the less powerful extract. Specifically, KTKT exhibits the lowest $\mathrm{IC}_{50}$ values at DPPH, plasmid relaxation assay and Ames Test compared with other extracts, a fact that indicates the importance of chemical polyphenolic composition to the activity of plant extracts. Such significant differences in the concentrations of polyphenols probably reflect the metabolic behavior of olive flower during the development stage on the basis of the genotype and the environmental conditions (40).

Regarding the effects of the tested extracts on myotube redox status, the extracts all increased GSH levels in all the tested cell lines compared with control. It is worth noting that in some cases (e.g., AGRI administration at HepG2 cells) when the concentration of the extract exhibited a threshold 
value, the endogenous levels of GSH decreased indicating a pro-oxidative phenomenon. The pro-oxidant effect caused by polyphenols depends on several factors, such as their chemical nature, concentration, and the micro-environmental conditions (e.g., the cell type, the redox state and the $\mathrm{pH}$ value) $(25,41)$. Olive oil polyphenolic extracts also had the ability to increase GSH levels through the Nrf2 pathway $(25,26,42)$. In addition, coffee polyphenols increased GSH both in vitro and in vivo as assessed in C2C12 and EA.hy296 cell lines (43) and in different tissues of Wistar rats (44), respectively, demonstrating an active role for the transcription factor $\mathrm{Nrf} 2$.

With respect to the chemical composition, HPLC analysis revealed the presence of common secondary metabolites in all the tested extracts. The AGRI, EKPA and ANKT extracts had similar absorbance in all tested wavelengths (i.e., 254, 280 and $355 \mathrm{~nm}$ ) with maximum absorbance at $254 \mathrm{~nm}$ and retention time, 15-35 $\mathrm{min}$. The tree main compounds found in these extracts are Quercetin-3-O-sophoroside (retention time $21.5 \mathrm{~min}$ ), Rutin (retention time $23.75 \mathrm{~min}$ ) and oleuropein (retention time $30.0 \mathrm{~min}$ ). By contrast, for KTKT extract, which was collected earlier in comparison to other samples, low absorbance values were depicted at $254 \mathrm{~nm}$ while only a trace of oleuropein was found. In a study focused on olive blossoms from the Tunisia cultivar 'Chemlali' it appeared that the oleuropein levels were increased with a concomitant increase of flower maturation period (21).

On the basis of our results, all tested olive flower extracts exhibited potent antioxidant, antimutagenic and antigenotoxic activities. Furthermore, they improved redox status at the cellular level as indicated by the enhancement of the GSH values and the reduced ROS levels. Olive tree flowers are considered as by-products of olive oil production. Taking into account that during olive tree cultivation a considerable amount of olive flowers is generated, the burden of environmental pollution is high. Given the optimistic findings we present in this study, we believe that although further relevant in vivo studies are required, the flower-derived extracts could have high added since they could be used as antioxidants or as foodstuffs, food additives and functional food constituents.

\section{Acknowledgements}

Not applicable

\section{Funding}

The study was funded by the Hellenic General Secretariat for Research and Technology (GSRT) and the Hellenic Foundation for Research and Innovation (HFRI) (grant no. 5547).

\section{Availability of data and materials}

The datasets used during the present study are available from the corresponding author upon reasonable request

\section{Authors' contributions}

PK, DK and ALS conceived the study. The research methodology was designed by PK, DK, ALS and AA. Formal analysis of the data was conducted by PK. Software analysis of data and figures was conducted by PK, and supervision of the research was conducted by DK and ALS. Writing of the original draft was undertaken by PK and AA, and review and editing of the manuscript were carried out by ASV, ALS and DK. The experimental procedures were conducted by PK, FT, KV, PM and AA. All authors read and approved the final manuscript.

\section{Ethics approval and consent to participate}

Not applicable.

\section{Patient consent for publication}

Not applicable

\section{Competing interests}

All the authors declare that they have no competing interests.

\section{References}

1. Riley FR: Olive oil production on bronze age crete: Nutritional properties, processing methods and storage life of Minoan olive oil. Oxford J Archaeol 21: 63-75, 2002.

2. Bouknana D, Hammouti B, Jodeh S, Sbaa M and Lgaz H: Extracts of olive inflorescence flower pre-anthesis, at anthesis and grain pollen as eco-friendly corrosion inhibitor for steel in $1 \mathrm{M} \mathrm{HCl}$ medium. Anal Bioanal Electrochem 10: 751-777, 2018.

3. De Leonardis A, Aretini A, Alfano G, MacCiola V and Ranalli G: Isolation of a hydroxytyrosol-rich extract from olive leaves (Olea Europaea L.) and evaluation of its antioxidant properties and bioactivity. Eur Food Res Technol 226: 653-659, 2008.

4. Lafka T-I, Lazou A, Sinanoglou V and Lazos E: Phenolic Extracts from Wild Olive Leaves and Their Potential as Edible Oils Antioxidants. Foods 2: 18-31, 2013.

5. Pandey KB and Rizvi SI: Plant polyphenols as dietary antioxidants in human health and disease. Oxid Med Cell Longev 2: $270-278,2009$.

6. Rekik O, Ben Mansour A and Bouaziz M: Evaluation of phenolic composition and antioxidant activity changes in olive flowers during development using HPLC/DAD and LC-MS/MS. Electrophoresis 39: 1663-1672, 2018.

7. Lavee S, Rallo L, Rapoport HF and Troncoso A: The floral biology of the olive: Effect of flower number, type and distribution on fruitset. Sci Hortic (Amsterdam) 66: 149-158, 1996.

8. Griggs, W.H., Hartman, H.T., Bradley, M.V., Iwakiri, B.T. and Whistler JE: Olive polination in Claifornia. Calif Agric Exp Sta Bull 869: 50 pp, 1975.

9. Fabbri A and Benelli C: Flower bud induction and differentiation in olive. J Hortic Sci Biotechnol 75: 131-141, 2000.

10. Cuevas J and Polito VS: The role of staminate flowers in the breeding system of Olea europaea (Oleaceae): an andromonoecious, wind-pollinated taxon. Ann Bot 93: 547-553, 2004.

11. Kishikawa A, Ashour A, Zhu Q, Yasuda M, Ishikawa $\mathrm{H}$ and Shimizu K: Multiple biological effects of olive oil by-products such as leaves, stems, flowers, olive milled waste, fruit pulp, and seeds of the olive plant on skin. Phytother Res 29: 877-886, 2015.

12. Blainski A, Lopes GC and De Mello JCP: Application and analysis of the folin ciocalteu method for the determination of the total phenolic content from limonium brasiliense L. Molecules, 2013.

13. Brand-Williams W, Cuvelier ME and Berset C: Use of a free radical method to evaluate antioxidant activity. LWT - Food Sci Technol 28: 25-30, 1995.

14. Kouka P, Priftis A, Stagos D, et al: Assessment of the antioxidant activity of an olive oil total polyphenolic fraction and hydroxytyrosol from a Greek Olea europea variety in endothelial cells and myoblasts. Int J Mol Med 40: 703-712, 2017.

15. Veskoukis A, Kerasioti E, Priftis A, Kouka P, Spanidis Y, Makri S and Kouretas D: A battery of translational biomarkers for the assessment of the in vitro and in vivo antioxidant action of plant polyphenolic compounds: The biomarker issue. Curr Opin Toxicol 13: 99-109, 2018. 
16. Cano A, Hernández-Ruíz J, García-Cánovas F, Acosta $M$ and Arnao MB: An end-point method for estimation of the total antioxidant activity in plant material. Phytochem Anal 9: 196-202, 1998.

17. Maron DM and Ames BN: Revised methods for the Salmonella mutagenicity test. Mutat Res 113: 173-215, 1983.

18. Priftis A, Papikinos K, Koukoulanaki M, et al.: Development of an assay to assess genotoxicity by particulate matter extract. Mol Med Rep 15: 1738-1746, 2017.

19. Bal-Price A and Coecke S: Guidance on Good Cell Culture Practice (GCCP). Neuromethods 56: 1-25, 2011.

20. Kouka P, Priftis A, Stagos D, et al.: Assessment of the antioxidant activity of an olive oil total polyphenolic fraction and hydroxytyrosol from a Greek Olea europea variety in endothelial cells and myoblasts. Int J Mol Med 40: 703-712, 2017.

21. Abaza L, Taamalli A, Arraez-Roman D, Segura-Carretero A, Fernandez-Gutierrerez A, Zarrouk $\mathrm{M}$ and Youssef $\mathrm{N}$ Ben: Changes in phenolic composition in olive tree parts according to development stage. Food Res Int 100: 454-461, 2017.

22. Ceylan Y, Usta K, Usta A, Maltas E and Yildiz S: Evaluation of antioxidant activity, phytochemicals and ESR Analysis of Lavandula Stoechas. In: Acta Physica Polonica A 128: B-483B-487, 2015.

23. Brahmi F, Mechri B, Dhibi M and Hammami M: Variation in antioxidant activity and phenolic content in different organs of two Tunisian cultivars of Olea europaea L. Acta Physiol Plant 36: 169-178, 2014.

24. Moudache M, Colon M, Nerin C and Zaidi F: Phenolic content and antioxidant activity of olive by-products and antioxidant film containing olive leaf extract. Food Chem 212: 521-527, 2016.

25. Kouka P, Priftis A, Stagos D, et al.: Assessment of the antioxidant activity of an olive oil total polyphenolic fraction and hydroxytyrosol from a Greek Olea europea variety in endothelial cells and myoblasts. Int J Mol Med 40: 703-712, 2017.

26. Kouka P, Tsakiri G, Tzortzi D, Dimopoulou S, Sarikaki G, Stathopoulos P, Veskoukis AS and Halabalaki MSA-L: The poly-phenolic composition of extracts derived from different greek extra virgin olive oils is correlated with their antioxidant potency. Oxid Med Cell Longev 2019: 13, 2019.

27. Cheng Z, Ren J, Li Y, Chang W and Chen Z: Study on the multiple mechanisms underlying the reaction between hydroxyl radical and phenolic compounds by qualitative structure and activity relationship. Bioorg Med Chem 10: 4067-4073, 2002.

28. Wright JS, Johnson ER and DiLabio GA: Predicting the activity of phenolic antioxidants: theoretical method, analysis of substituent effects, and application to major families of antioxidants. J Am Chem Soc 123: 1173-1183, 2001.

29. Priftis A, Mitsiou D, Halabalaki M, Ntasi G, Stagos D, Skaltsounis LA and Kouretas D: Roasting has a distinct effect on the antimutagenic activity of coffee varieties. Mutat Res 829-830: 33-42, 2018.

30. Amereh Z, Hatami N, Shirazi FH, et al.: Cancer chemoprevention by oleaster (Elaeagnus angustifoli L.) fruit extract in a model of hepatocellular carcinoma induced by diethylnitrosamine in rats. EXCLI J 16: 1046-1056, 2017.
31. Abaza L, Talorete TP, Yamada P, Kurita Y, Zarrouk M and Isoda $\mathrm{H}$ : Induction of growth inhibition and differentiation of human leukemia HL-60 cells by a Tunisian gerboui olive leaf extract. Biosci Biotechnol Biochem 71: 1306-1312, 2007.

32. Akl MR, Ayoub NM, Mohyeldin MM, Busnena BA, Foudah AI, Liu Y-Y and Sayed KAE: Olive phenolics as c-Met inhibitors: $(-)$-Oleocanthal attenuates cell proliferation, invasiveness, and tumor growth in breast cancer models. PLoS One 9: e97622, 2014.

33. Pampaloni B, Mavilia C, Fabbri S, et al.: In Vitro Effects of Extracts of Extra Virgin Olive Oil on Human Colon Cancer Cells. Nutr Cancer 667: 1228-1236, 2014.

34. De Leonardis A, Aretini A, Alfano G, MacCiola V and Ranalli G: Isolation of a hydroxytyrosol-rich extract from olive leaves (Olea Europaea L.) and evaluation of its antioxidant properties and bioactivity. Eur Food Res Technol 226: 653-659, 2008.

35. El-Kholy TA, Hilal MA, Al-Abbadi HA, Serafi AS, Al-Ghamdi AK, Sobhy HM and Richardson JRC: The effect of extra virgin olive oil and soybean on dna, cytogenicity and some antioxidant enzymes in rats. Nutrients 6: 2376-2386, 2014.

36. Zeriouh W, Nani A, Belarbi M, et al: Phenolic extract from oleaster (Olea europaea var. Sylvestris) leaves reduces colon cancer growth and induces caspase-dependent apoptosis in colon cancer cells via the mitochondrial apoptotic pathway. PLoS One 12: 1-19, 2017.

37. Salvini S, Sera F, Caruso D, et al.: Daily consumption of a highphenol extra-virgin olive oil reduces oxidative DNA damage in postmenopausal women. Br J Nutr 95: 742-751, 2006.

38. Cano-Lamadrid M, Marhuenda-Egea FC, Hernandez F, RosasBurgos EC, Burgos-Hernandez A and Carbonell-Barrachina AA: Biological Activity of Conventional and Organic Pomegranate Juices: Antioxidant and Antimutagenic Potential. Plant Foods Hum Nutr 71: 375-380, 2016.

39. Kirkland D, Edwards J, Woehrle T and Beilstein P: Investigations into the genotoxic potential of olive extracts. Mutat Res Genet Toxicol Environ Mutagen 777: 17-28, 2015.

40. Leopoldini M, Russo N and Toscano M: The molecular basis of working mechanism of natural polyphenolic antioxidants. Food Chem, 2011.

41. Leon-Gonzalez AJ, Auger C and Schini-Kerth VB: Pro-oxidant activity of polyphenols and its implication on cancer chemoprevention and chemotherapy. Biochem Pharmacol 98: 371-380, 2015.

42. Kouka P, Chatzieffraimidi G-A, Raftis G, et al: Antioxidant effects of an olive oil total polyphenolic fraction from a Greek Olea Europaea variety in different cell cultures. Phytomedicine 47: 135-142, 2018.

43. Priftis A, Goutzourelas N, Halabalaki M, et al: Effect of polyphenols from coffee and grape on gene expression in myoblasts. Mech Ageing Dev 172: 115-122, 2018.

44. Priftis A, Soursou V, Makiou A-S, et al: A lightly roasted coffee extract improves blood and tissue redox status in rats through enhancement of GSH biosynthesis. Food Chem Toxicol 125: 305-312, 2019. 